\title{
Do fim da ditadura Argentina ao movimento piqueteiro: origens e desafios da organização dos desempregados ${ }^{1}$.
}

\author{
From the end of the argentine dictatorship to the piqueteiro movement: Origins and \\ challenges of the organization of the unemployed
}

\section{Soraia de Carvalho*}

\begin{abstract}
Resumo:
Este artigo apresenta o movimento piqueteiro como uma das tentativas de reorganização dos trabalhadores argentinos no período pós-ditadura militar (1973-1986). Expõe as origens deste movimento de desempregados: os levantes populares nas cidades petroleiras devastadas pelas privatizações que acompanham a implementação do modelo neoliberal e as organizações territoriais influenciadas pelas Comunidades Eclesiais de Base. Problematiza a relação com as políticas assistenciais, ponto que define as bandeiras de luta dos distintos movimentos piqueteiros, revelando sua adequação ou confronto com o Estado.
\end{abstract}

Palavra-chave: Organização; Desempregados; Movimento Piqueteiro; Autonomismo; políticas assistenciais.

\begin{abstract}
:
This article presents the piquetero movement as one of the attempts to reorganize the workers in the Argentine post- military dictatorship (1973-1986). Explains the origins of this movement of the unemployed: the popular uprisings in cities devastated by oil privatization that accompany the implementation of the neoliberalism model and the territorial organizations affected by Base Ecclesial Communities. Problematizes the relationship with assistance policies, which defines the point of battle flags of the different piquetero movements, revealing its adequacy or confrontation with the State.
\end{abstract}

Key words: Organization; Unemployed; Piquetero Movement; Autonomism; Assistance Policies.

\section{Introdução}

Com a ditadura militar de 1976-1983, o movimento operário foi duramente golpeado com a sistemática eliminação da vanguarda que se organizava nas fábricas,

1 Este artigo é fruto da dissertação de mestrado Lutas sociais, piqueteiros e autonomismo: a experiência político-ideológica da Frente Popular Dário Santillán, Universidade Estadual de Londrina, 2008.

* Mestre em Ciências Sociais pela UEL e pesquisadora do GEPAL (Grupo de Estudos de Política da América Latina), e-mail: soraiadecarvalho@hotmail.com 
sindicatos, bairros, partidos e organizações de esquerda. Mas isto não fez do governo de Raúl Alfonsín (1983-1989), do partido União Cívica Radical, presidente eleito em outubro de 1983, um período tranqüilo.

Além das greves e manifestações sindicais, organismos de Direitos Humanos surgidos na última ditadura, como as Madres e Abuelas de la Plaza de Mayo e a CONADEP (Comisión Nacional sobre la Desaparición de Personas) pressionavam o governo para que os militares fossem punidos pelo saldo de 30 mil "desaparecidos". Em 1985, integrantes das três primeiras juntas militares foram levados a julgamento. A resposta corporativa das Forças Armadas levou aos levantes dos "carapintadas", seguida por manifestações populares massivas em defesa da manutenção do regime democrático (ainda que limitado). Alfonsín recuou e aprovou as leis de Obediência Devida e Ponto Final, garantindo a impunidade dos militares envolvidos em torturas e assassinatos.

A economia argentina, sufocada pela dívida externa, sofria com a hiperinflação, em 1987, com o esgotamento do Plano Austral, a inflação se acelerou. Neste período, os setores mais empobrecidos da sociedade realizaram muitos saques (CARRERA; COTARELO, 2000 , p. 173). Diante dos conflitos sociais, o presidente encurtou seu mandato, sendo sucedido pelo justicialista Carlos Menem.

A década menemista (1989-1999) se dá no contexto de realização do Consenso de Washington, que marca a expansão do projeto neoliberal pela América Latina. Assim, o Estado argentino promoveu a acelerada privatização das empresas públicas e "desregulamentou" os mercados. Com o plano de convertibilidade, de 1991, estabeleceuse a paridade entre peso e dólar, as barreiras alfandegárias foram reduzidas, os serviços básicos e a previdência pública, foram drasticamente afetados com a redução de gastos sociais. Os trabalhadores também foram golpeados com a aprovação da Lei Nacional de Emprego, que com a "flexibilização" eliminou direitos e acentuou a precariedade no trabalho.

Segundo Eduardo Lucita,

[...] la fuerte disputa al interior de las clases dominantes por la apropiación de la riqueza social, que fuera una de las características de todo el período anterior (a 1976), se cierra en 1991. Es en torno al Plan de Cnvertibilidad que se logra disciplinar a las distintas fracciones de la burguesía que asumen así un programa común bajo la hegemonía del capital financiero (apud KOHAN, 2002, p. 11). 
O impacto desta política pode ser percebido no balanço da década de 1990, que viu a população economicamente ativa crescer $28 \%$, enquanto a ocupação plena aumentou 9\%, o desemprego e o subemprego elevaram-se vertiginosamente, $156,3 \%$ e $115,4 \%$, respectivamente. A taxa de desemprego, que em 1990 era de 6\%, triplicou em 1996 e chegou a 21,5\% em maio de 2002 (SVAMPA; PEREYRA, 2004, p. 22).

Segundo Carrera e Cotarelo (2004, p. 126), o ano de 1993 marcou um ascenso nas lutas sociais, iniciado com o motim de Santiago del Estero, umas das províncias mais pobres da Argentina. A partir de uma greve contra a demissão de dez mil servidores municipais e redução salarial do restante, a população expressou o descontentamento com o desemprego crescente. O movimento converteu-se em uma revolta popular, culminando com a queima de edifícios públicos, ataques a residências de políticos burgueses e confrontos com o aparato repressivo do Estado. Para Luis Oviedo (2001, p.11), o piquete como ferramenta política foi um filho direto do Santiagazo. Depois disso, nas lutas protagonizadas lá e em outras províncias, já aparecem os cortes de ruta, ocupações de fábricas e edifícios governamentais, ações nas ruas e assembléias (MANSILLA; CONTI, 2003, pp. 40-41).

Com o agravamento do desemprego, iniciam-se os primeiros movimentos cuja base principal era composta pelas vítimas das privatizações e do fechamento de fábricas. Em 1995, em Neuquén surge a primeira coordenadora de desempregados. Nesta província do norte da Patagônia, a construção de grandes obras como hidrelétricas e a extração do petróleo propiciaram uma expressiva concentração operária. Em 1984 e 1986 (com a Caminata de Piedra de Águila, em que houve bloqueios de rodovias), trabalhadores da construção civil protagonizaram greves massivas e radicalizadas. Como efeito das privatizações e fim das grandes obras, a década de 1990 é marcada pela falta de trabalho. Em 1994, o índice de desemprego de $20 \%$ na Província alcançava 50\% nos bairros operários.

Muitos enfrentavam o desemprego também pela perseguição política por conta da participação em movimentos anteriores. Assim, começaram a organizar nos bairros um "censo" que ao mesmo tempo em que identificava os desempregados, os convidava para que se organizassem em assembléias por bairro, elegendo delegados para a Coordenadora, que deveria ter um programa e organização comuns, capazes de exigir do 
Estado suas reivindicações. As bandeiras principais eram: divisão das horas de trabalho entre todos trabalhadores e salário de acordo com o custo de vida. Os subsídios eram vistos pela Coordenadora como uma "política del Gobierno, la Iglesia y la Burocracia sindical, y pretendia descomprimir y bloquear la organización independiente de los obreros sin trabajo" (POR, 1995, p.33). Mas diante da situação de fome e miséria a que estavam submetidos estes trabalhadores, a coordenadora incorporou a reivindicação de subsídio de 500 pesos por tempo indeterminado.

Em 29 de agosto de 1995, manifestantes ocuparam a municipalidade, mantiveram o prefeito refém, conseguindo que todos recebessem subsídios, sem contra-prestação de trabalho. Nesta primeira experiência, já se expressaram os principais debates futuros: a defesa do trabalho genuíno ou subsídio, a questão da organização dos desempregados, a definição de classe desta camada social (lúmpens ou parte das classes trabalhadoras)² e, sobretudo, o enfrentamento à repressão estatal.

Com a prisão de um dos dirigentes, Horacio Panario, militante do MAS (Movimiento al Socialismo), e ordem de captura de vários militantes, houve uma campanha de repercussão nacional e internacional. Uma das primeiras organizações de desempregados da Grande Buenos Aires, em La Matanza, dirigida por Hector "Toty" Flores', na ocasião militante do MAS, teve sua primeira manifestação pública nesta campanha (MANSILLA; CONTI, 2003, pp. 46-47).

Como uma maneira de dividir o movimento, o governo sancionou a lei 2128 , a primeira lei de subsídios a desempregados no país, que já limitava quem poderia recebêlos, inclusive com critérios contra imigrantes. O nome de "piqueteiros" ainda não era conhecido, mas o desemprego já era a maior preocupação na província.

2 A organização de desempregados em Neuquén foi alvo de críticas. A Corriente de Trabajadores Clasistas (CTC) alegava que "[...] el sector de desocupados esta compuesto en el capitalismo por un LUMPEMPROLETARIADO por un lado compuesto por elementos depravados de otras clases sociales" (CTC apud POR, 1995, p. 24). O Partido Operário Revolucionário (POR), que era parte da direção do movimento discordava desta caracterização: "Según la CTC, un obrero que está desocupado es LÚMPEN, si consigue trabajo pasa a ser proletario, cuando le apliquen la flexibilización laboral (unos pocos meses por contrato), volverá a ser despedido para transformarse nuevamente en Lúmpen y rogará para conseguir trabajo y ser considerado nuevamente un proletario" (POR, 1995, p. 36).

3 Ex-metalúrgico e dirigente do MTD La Juanita, Toty Flores. Saindo do MAS tornou-se defensor do autonomismo e da auto-gestão. Posteriormente, em 2007, foi eleito deputado nacional pelo partido ARI Alternativa para una República de Iguales e passou a ser referência de "empreendedorismo". 


\section{O nome "piqueteiro" ecoa por todo o país}

Os cortes de ruta - bloqueios de rodovias, com barricadas que isolavam cidades, paralisando a circulação de mercadorias - têm seu início em 1996, em Cutral-Có e Plaza Huincul, cidades petroleiras ${ }^{4}$ na província de Neuquén. Com 57 mil habitantes, neste ano o desemprego já atingia 30\% da População Economicamente Ativa (KOHAN, 2002, p. 22). Ironicamente, as primeiras manifestações foram convocadas por conta de disputas internas entre facções do partido governante, o MPN (Movimiento Popular Neuquino). Opositores ao governador Felipe Sapag convocaram um bloqueio de rodovia contra o cancelamento da vinda de uma empresa que traria dois mil empregos para a região, devastada pela privatização da YPF em 1991. As manifestações logo cresceram e fugiram ao controle do MPN. Segundo Mariela Suárez, que participou dos levantes populares de 1996 e 1997, sendo eleita representante da Assembléia Popular de Cutral-Có durante a pueblada ${ }^{5}$ de 1997:

\footnotetext{
La protesta comienza generada por una línea del MPN, pero la realidad fue que la gente se sumó porque la necesidad de trabajo era un reclamo verdadero, era genuino porque después de la privatización de YPF no quedó nada.

[...] Esta primera pueblada fue mucho más masiva, era como más genuina, en su origen no, pero después sí.

[...] Primero escuchaba por la radio, me daba mucha bronca, y después pensamos: para que vamos quedarnos acá masticando bronca, vamos y planteamos la discusión (SUÁREZ, 2006). ${ }^{6}$
}

Constituíram-se Assembléias Populares, das quais participavam cerca de cinco mil pessoas. O Estado recorreu à repressão, mas a juíza que permitiu a ação repressiva, ao ir até o piquete, diante de 20 mil manifestantes se declarou incompetente, por estar diante do crime de sedição e ordenou a retirada das tropas (SVAMPA; PEREYRA, 2004, p. 113). Após isto, o governador teve de negociar. As manifestações foram encerradas, mas grande parte do prometido não foi cumprido. Os piqueteiros que negociaram foram acusados de traição, por terem sido posteriormente beneficiados individualmente.

\footnotetext{
4 A empresa, que em 1990 contava com 51 mil empregados, após a privatização manteve apenas 5.600, Em Neuquén, foram 4.246 demissões. Em Tartagal e Mosconi (Salta), houve uma queda de $75 \%$ no índice de empregos (BERACOCHEA; ESQUERRO et al apud SVAMPA; PEREYRA, 2004, p.108).

5 Puebladas são levantes populares policlassistas.

6 Entrevista realizada em Cutral-Có (Neuquén) em 26 de outubro de 2006.
} 
Como um balanço desta primeira pueblada os autores destacam que: o permanente funcionamento assembleário tensionou ao máximo todas as instâncias de representação e mediação; o surgimento de novas lideranças deslocou os atores institucionais vinculados a interesses políticos e econômicos da classe dominante; mas com a reabsorção destas novas lideranças por parte da política local, só resultados de curto prazo foram garantidos pelo movimento. Mariela Suárez ressalta que o limite desta experiência foi que não resultou em organização, o que seria necessário para manter um controle das reivindicações e conquistas.

Com o início do ano letivo, em 1997, os docentes iniciaram uma greve por reivindicações econômicas imediatas e contra a Lei Educativa Federal, que mutilava direitos. A greve massiva se radicalizou e os docentes passaram a utilizar os métodos piqueteiros, bloqueando os acessos a Neuquén. A gendarmeria - polícia militar federal responsável pelas fronteiras, mas que é utilizada frequentemente para debelar movimentos - reprimiu violentamente os manifestantes. Em Cutral-Có surgiram bloqueios em solidariedade à luta docente, mas os protagonistas eram os fogoneros, pois pelo desfecho do levante popular do ano anterior, a palavra "piqueteiro" passou a ser mal vista. Segundo Ariel Petruccelli (2005, p. 110), os fogoneros eram jovens que tinham problemas com a polícia nos bairros, por pequenos furtos e pela repressão constante. Svampa e Pereyra (2004) caracterizam este grupo também por incluir os que enfrentaram as forças policiais na pueblada anterior sem obter nenhum benefício. No movimento, eram incontroláveis, céticos quanto à ação política de partidos, sindicatos, contra qualquer organização. Eram o setor mais firme dos piquetes, mas quase não participavam das assembléias. No confronto com a gendarmeria, fizeram as forças repressivas recuarem em diversos momentos, utilizando apenas armas "caseiras", pedras e táticas de enfrentamento, recuo e reorganização.

Durante a repressão, Tereza Rodriguez, uma empregada doméstica e manifestante, foi assassinada pela polícia em 12 de abril. No mesmo dia, o sindicato docente negociou o fim da greve com o governador, o que foi visto como traição por um setor dos docentes e, sobretudo, pelos fogoneros. Mas a pueblada de Cutral-Có continuou. A assembléia popular elegeu uma comissão de negociação com mandatos revogáveis e rotativos, uma medida antiburocrática que buscava inviabilizar a cooptação e traições. Os pontos não 
cumpridos no ano anterior voltaram à pauta de reivindicações. Mantiveram-se os confrontos com a polícia, envolvendo praticamente toda a cidade. Com a oferta do cumprimento parcial das reivindicações, a assembléia suspendeu o bloqueio, contra a vontade dos fogoneros. A possiblidade deste setor voltar a se mobilizar foi tratada como um problema do Estado e até mesmo da petroleira privatizada Repsol-YPF, que interveio oferecendo diretamente aos fogoneros 500 planos assistenciais de 400 pesos por dois anos.

A cidade que deu origem aos piqueteiros não manteve nenhum movimento autônomo de desempregados com atuação significativa na vida política local. Mesmo após duas puebladas muito radicalizadas, os setores em luta foram canalizados para vias institucionais, irrigadas com ampla distribuição de Planos Assistenciais (Planes Trabajar) e verbas para a criação de pequenos empreendimentos. O empenho do Estado em descomprimir a situação foi tamanho que $13 \%$ da população economicamente ativa passaram a receber planos assistenciais.

O saldo mais importante do Cutralcazo foi sua influência nas revoltas em outros pontos do país, como as cidades petroleiras de Tartagal y General Mosconi - Salta, demonstrando a necessidade da ação direta e coletiva e a eficácia em forçar negociações por meio dos cortes de ruta, permitindo a setores que não estavam nas fábricas, afetar momentaneamente a produção das mercadorias, bloqueando sua circulação.

\section{Efeito dominó: Salta, Jujuy, Tucumán e Córdoba}

Pouco depois dos cortes de ruta em Neuquén, ainda em 1997, as manifestações em Salta (General Mosconi e Tartagal), Jujuy, Tucumán e Córdoba deram visibilidade à chamada "crise do interior". Se a pueblada neuquina alarmou os governos locais quanto à questão do desemprego, a seqüência de lutas evidenciou que este era um problema nacional. Deter-nos-emos nas lutas ocorridas em Salta, pela contribuição quanto a um "modelo" organizativo que teve forte presença nas subseqüentes organizações piqueteiras. Nas cidades de Tartagal e Mosconi (Salta), também manifestações por reivindicações econômicas imediatas se converteram em puebladas incontroláveis, que enfrentaram repressão e tentativas de cooptação, mas houve diferenças significativas em relação à experiência neuquina. 
O movimento começou a partir do descontentamento da população quanto ao funcionamento da fornecedora local de energia elétrica. Moradores se organizaram em assembléias e decidiram bloquear, o que deveria durar horas, ultrapassou a expectativa dos organizadores. Ao longo dos sete dias de bloqueio foram se somando outros setores, conformando uma multisetorial. As ações também foram se espalhando para outras localidades próximas. Após a ameaça de repressão e com a ação conciliadora da Igreja, as rodovias foram desbloqueadas. Os pontos do acordo indicam a amplitude desta multisetorial, há itens que favorecem trabalhadores empregados e desempregados, comunidades indígenas e até empresários do setor madeireiro e agropecuário.

Em 1999, diante de uma greve dos servidores públicos, desempregados se somaram, expressando organização e reivindicações próprias. Com o bloqueio das rodovias, o governo retrocedeu em seu plano de demitir servidores e em vez de retirar os cerca de dois mil planos assistenciais para desempregados, teve de criar mais três mil. Posteriormente, se constituiu a UTD (Unión de Trabajadores Desocupados). Segundo Svampa e Pereyra (2004, p. 129), "a partir del establecimiento de esa dinámica de obtención y control de planes, las organizaciones piqueteras adquieren relevancia y capacidad de maniobra en el contexto de la política local". Nacionalmente as dificuldades de articulação eram grandes, mas em Mosconi a UTD conseguia manter-se unificada, agregando os principais dirigentes locais e ganhando credibilidade por seu trabalho junto à comunidade, o que respaldava as medidas de ação direta, às quais distintos setores sociais se somavam.

Em maio de 2000, quando se realizava o terceiro grande bloqueio e a primeira pueblada em Mosconi, a UTD já estava consolidada. A manifestação também foi convocada por disputas internas no peronismo, e conflitos entre governos locais e o governo provincial e nacional. O protesto extrapolou os objetivos iniciais e os piqueteiros expuseram suas reivindicações próprias de fim de processos contra militantes e aumento de Planes Trabajar. Com a intervenção da gendarmeria, depois de muito confronto, a rodovia foi liberada e as principais reivindicações foram conquistadas: aumento de 1.600 para 3.000 subsídios e libertação de 43 presos.

Em novembro do mesmo ano, durante a repressão a um bloqueio em Tartagal e Mosconi, o motorista Aníbal Verón foi assassinado, provocando a ocupação de prédios 
públicos, comércios privados e muitos enfrentamentos com as forças policiais. Em 2001, ao mesmo tempo em que a UTD dava "conteúdo" aos planos assistenciais, com microempreendimentos produtivos, os bloqueios continuaram. Em junho houve mais dois piqueteiros assassinatos em ações repressivas do Estado.

$\mathrm{Na}$ região houve uma articulação maior entre duas gerações: a dos extrabalhadores da YPF (operários qualificados) com a maioria de jovens (com pouca qualificação e escassa ou nula experiência profissional), com isso, além das demandas por planos assistenciais, houve inclusive a reincorporação de trabalhadores demitidos da YPF. Nas negociações também se reivindicava a redução da jornada de trabalho, pagamento de horas extras, elevação de salários, dentre outras bandeiras.

Comparando a resposta dos governos locais, observamos que em Neuquén houve um grande esforço de contenção das lutas dos desempregados com o discurso de "retomar a produção". Em Salta, a própria UTD se encarregou de desenvolver um discurso em defesa do "desenvolvimento". Assim, ao mesmo tempo em que se confronta com o Estado, a UTD tem um funcionamento em que acaba entrando na lógica e estrutura administrativa, intermediando a relação entre empresas e o Estado em obras públicas e até mesmo escalando um dirigente para participar do governo local como Secretário do Trabalho, com aval da assembléia do movimento.

Por outro lado, as atividades da UTD criaram um "modelo" de condução de projetos produtivos, para as organizações piqueteiras autonomistas, principalmente o MTR (Movimiento Teresa Rodríguez) e MTDs da Coordinadora de Trabajadores Desocupados Aníbal Verón.

As experiências de Neuquén e Salta constituem uma das origens do movimento piqueteiro, gerado a partir das cidades petroleiras, que em seus levantes registraram o poder da organização coletiva, das assembleias massivas e controle das vias de circulação das mercadorias. Encontra-se aí também, o padrão no modo de agir das classes dominantes. O traço comum foi o uso da repressão do Estado, mas diante da combatividade destes setores isto foi insuficiente para derrotar estes levantes populares. Em Neuquén, a saída encontrada pelo governo local foi a da "contenção" social por meio da institucionalização e assistencialismo. Em Mosconi, a continuidade do movimento se deu com as ambiguidades dos empreendimentos produtivos, que por um lado expressam 
a auto-organização dos explorados e por outro o controle do Estado por meio de financiamentos a estas atividades.

\section{A origem territorial}

Com o processo de "desindustrialização" e deterioração das condições de vida do proletariado e pequena burguesia empobrecida, na década de 1970, criou-se o cenário para o surgimento de movimentos centrados nos bairros da grande Buenos Aires, Rosário e Mar del Plata. Em geral, organizaram-se assentamentos a partir da intervenção das Comunidades Eclesiais de Base e organizações de direitos humanos (SVAMPA; PEREYRA, 2004 , p. 39). Estes atores foram se constituindo na luta pela propriedade destas terras e na reivindicação de serviços básicos (asfalto, água, energia elétrica, atendimento médico etc.).

A maior parte das organizações piqueteiras que priorizam um trabalho territorial, como a FTV (Federación Tierra y Vivienda), CCC (Corriente Clasista y Combativa), MTR (Movimiento Teresa Rodríguez) e a "La Verón" são continuidade destas experiências. A emergência das organizações piqueteiras na grande Buenos Aires data de 1995. O surgimento em La Matanza não é ocasional. Este distrito de Buenos Aires possui dois milhões de moradores, em sua maioria, concentrados em bairros operários e assentamentos. Com os ajustes neoliberais, o antigo polo industrial foi praticamente convertido em um cemitério de fábricas. Em setembro de 1996, a marcha contra a fome, repressão e desemprego junta duas colunas: uma parte de La Matanza, encabeçada por Toty Flores e a outra por incipientes movimentos da zona sul de Buenos Aires. São estes os que em 1997 realizarão os primeiros cortes de ruta e receberão os primeiros planos assistenciais. Percebendo este surgimento a CTA lança a consigna: "La nueva fábrica es el barrio", criando sua organização de desempregados, a FTV.

\section{Confronto e adequação à rede assistencialista do Estado}

Para avaliar como os movimentos piqueteiros se relacionam com 0 assistencialismo, reconstituiremos a atuação do Estado no pós-ditadura. No governo de Raúl Alfonsín, em 1983, foi criado o PAN - Plan Alimentario Nacional - em que eram 
distribuídas caixas de alimentos (MASSETI, 2007). Com os primeiros piquetes e puebladas já no governo Menem, entrou em cena o Plan Trabajar I, elaborado e financiado diretamente pelo Banco Mundial. O assistencialismo focalizado tinha o nítido objetivo de conter os protestos e não a pobreza, afinal eram cerca de 150 mil beneficiados com subsídios de 150 pesos durante três a seis meses em um contingente de cinco milhões de desempregados (OGANDO, 2004). O discurso de combate ao desemprego também esteve presente na "nova lei de emprego", que ao destruir direitos trabalhistas prometia que a economia privada seria dinamizada. Assim o Estado possibilitava novas contratações, mas sem direitos plenos.

Mesmo tendo ocorrido em nível provincial, a política de Duhalde na província de Buenos Aires, de 1994 a 1999, deve ser destacada, tanto por ter criado a rede das manzaneras $^{7}$ que depois se integram aos movimentos piqueteiros, como por antecipar sua política pós-Argentinazo, quando ocupou a presidência do país. A rede assistencial de Duhalde recrutava nos bairros duas mulheres a cada quarteirão, somando 37 mil manzaneras que distribuíam diariamente leite, ovos e cereais a um milhão de beneficiários de 50 municípios (ILARI, 1999). Este exército de mulheres tornou-se um importante elemento na máquina eleitoral do peronismo.

Nota-se que o surgimento das organizações piqueteiras em Buenos Aires são simultâneas à ação das manzaneras. Svampa e Pereyra destacam a ambigüidade destes agrupamentos em relação ao peronismo:

\begin{abstract}
Así, a partir de 1997 los discursos se van a teñir de denuncias sobre la escalada de una política de extorsión llevada a cabo por los punteros peronistas en los barrios. Por otro lado, la distancia entre las bases sociales de las organizaciones piqueteras y las formas de representación del peronismo político y sindical se acentuará y tomará rasgos críticos, en la medida en que el crecimiento de las organizaciones piqueteras se asienta también en la incorporación de referentes barriales peronistas, sobre todo de mujeres, manzaneras - para el caso de provincia de Buenos Aires - o punteras ${ }^{8}$ (2004, p. 195).
\end{abstract}

Em 1999, porém, a vitória eleitoral foi da Alianza, que reunia a UCR (União Cívica Radical) e Frepaso - Frente País Solidário -que somava a democracia cristã, Partido

70 nome refere-se a manzana, quarteirão.

80 punterismo político refere-se a uma rede clientelista vinculada aos partidos burgueses, principalmente ao Partido Justicialista. A atuação nos bairros periféricos objetiva controlar politicamente a população seja por meio do assistencialismo, da cooptação ou no embate físico com lideranças que ameacem seu domínio. 
Comunista, Partido Intransigente e setores provenientes do peronismo. A máquina assistencialista continuou ativa, mas mudou de mãos. A diferença é que para combater a presença peronista nos bairros, a Alianza passou a transferir o controle de parte dos planos assistenciais para as organizações de desempregados, o que ao mesmo tempo em que institucionalizou os movimentos, serviu de impulso à expansão destes. No governo do presidente Fernando de la Rúa houve um corte significativo nos planos. Segundo dados do Ministério do Trabalho, em outubro de 1997, havia 200 mil beneficiados com os Planes Trabajar I e II; dois anos depois eram 89 mil, dos quais só restaram 29 mil em maio de 2000:

En suma, la política del gobierno de la Alianza facilitó la proyección a la escena política nacional del actor piquetero, fortaleciendo a las grandes organizaciones y, al mismo tiempo, posibilitando que las más pequeñas se desarrollaran y adquirieran importantes márgenes de autonomía. Sin embargo, si el gran "salto" hacia la autonomía puede ser leído como una consecuencia indeseada, directamente relacionada con la nueva estrategia de implementación de los planes, su masificación lo es mucho menos. En realidad, ésta fue el resultado de una política de confrontación llevada a cabo por la totalidad de las organizaciones de desocupados, como respuesta a la disminución de planes sociales y a la falta de cumplimiento de lo acordado en los cortes de ruta en mayo de 2000, todo ello en un contexto de ajuste y mayor pauperización (SVAMPA; PEREYRA, 2004, p. 99).

É importante destacar que para poder controlar parte dos planos assistenciais, as organizações piqueteiras tiveram que criar ONG's (Organizações Não-Governamentais), sendo que esta era uma exigência do Estado, recomendada pelo Fundo Monetário Internacional e Banco Mundial.

\footnotetext{
Ya en el Informe Mundial de Desarrollo Humano de 1991 se considera que en tanto "organizaciones flexibles", las ONG son más eficaces en la respuesta para promover la participación popular y para trabajar en un nivel local, operando en zonas aisladas. Las ONG fueron conscientes de tal "mandato" o imperativo de desarrollar una nueva relación con el Estado y con los sectores populares, en convergencia con la política de descentralización, producto de la reforma estructural (SVAMPA; PEREYRA, 2004, p. 100).
}

Com a insurreição de 19 e 20 de dezembro de 2001, o presidente Fernando de la Rúa teve de renunciar. Eduardo Duhalde assumiu a presidência em janeiro de 2002, após cinco presidentes passarem pela Casa Rosada, em meio a um período de crescimento das lutas populares. Buscando conter os movimentos que protagonizavam cada vez mais 
ações universalizou o plano Jefas y Jefes de Hogar Desocupados. Em dezembro de 2001, $1 \%$ da População Economicamente Ativa recebia subsídios, em um ano este número chegou a $18 \%$, ou seja, 2,5 milhões de argentinos. Destes, $10 \%$ eram controlados pelas organizações piqueteiras, por meio de ONG's (FRAGA, 2003).

Durante o Governo de Néstor Kirchner (2003-2007), foi mantida a mesma estratégia, mas com algumas alterações: líderes piqueteiros foram incorporados a cargos no governo e, além dos grupos cooptados, foram criados MTD's kirchneristas (TOSI, 2006). A partir da legitimidade conquistada, Kirchner conseguiu acentuar a fragmentação dos setores em luta, enfraquecendo os que mantiveram uma postura crítica e reduzindo os subsídios, principalmente aos grupos opositores.

Assim, compreender a questão assistencial é fundamental para caracterizar o movimento de desempregados. O debate inicial (se a luta deveria ser por trabalho genuíno ou por subsídios) ainda hoje atravessa o cotidiano das organizações. Deve-se à resposta assistencial do Estado o sucesso quantitativo do movimento (em número de membros, estruturas nos bairros), mas ao mesmo tempo a sua maior fragilidade política, pois reforça uma relação de dependência em relação ao Estado.

\section{Referências}

CARRERA, N.I.; COTARELO, M. C. Algunos rasgos de la rebelión en Argentina 1993-2001. PIMSA, Buenos Aires, año 8, n. 8, p. 125-138, 2004.

La protesta social en los '90. Aproximación a una periodización. PIMSA, Buenos Aires, año 4, n. 4, 2000.

CTC. Carta abierta referente a los acontecimientos del 2 de octubre de 1995 sucedidos en Neuquén. Neuquén: 15 out. 1995.

FRAGA, R. Cambios políticos que se proyectan al nuevo año. La Nación, Bueno Aires, 5 jan. 2003. Disponível em: <http://www.lanacion.com.ar/463853>. Acesso em: 17 fev. 2007.

ILARI, S.R. El ¿plan vida?, dez. 1999. Disponível em: <www.fundasur.org.ar/elplanvida.htm>. Acesso em: 10 mar. 2007.

KOHAN, A. iA Las Calles! una historia de los movimientos piqueteros y caceroleros de los '90 al 2002. Buenos Aires: Colihue, 2002. 
LUCITA, E. Que venga lo que nunca ha sido. Cuadernos del Sur, Buenos Aires, n. 33, abr. 2002.

MANSILLA, I.S.; CONTI, R.A. Piqueteros: una mirada histórica. Buenos Aires: Astralib, 2003.

MASSETTI. A. Piqueteros eran los de antes": sobre las transformaciones en la Protesta Piquetera. Lavboratorio on line, Buenos Aires, año 7I, n. 19, 2006. Disponível em: <http://lavboratorio.fsoc.uba.ar/textos/19_5.htm>. Acesso em: 5 mar. 2007.

OGANDO, A. Desocupados y planes sociales en el pos-menemismo: 9 de abr. 2004. Rebelión. Disponível em: <http://www.rebelion.org/argentina/040409ogando.htm>. Acesso em: 5 mar. 2007.

OVIEDO, L. Una historia del movimiento piquetero. Buenos Aires: Rumbos, 2001.

PETRUCCELLI, A. Docentes y piqueteros: de la huelga de ATEN a la Pueblada de Cutral-Có. Buenos Aires: Ediciones El cielo por asalto, 2005.

POR. El movimiento de los trabajadores desocupados en el neuquén. Neuquén: Ediciones Masas, 1995.

SUÁREZ, M. Depoimento. Entrevistadora: Soraia de Carvalho. Cutral-Có, 26 out. 2006. 66 minutos. Arquivo em mp3.

SVAMPA, M.; PEREYRA, S. Entre la ruta y el barrio: la experiencia de las organizaciones piqueteras. 2. Ed. Buenos Aires: Biblos, 2004.

TOSI. M.C. Una red con piqueteros y "margaritas". La Nación, Buenos Aires, 4 set. 2006. Disponível em:

<http://www.lanacion.com.ar/EdicionImpresa/politica/nota.asp?nota_id=837533>. Acesso em: 12 fev. 2007. 